\title{
Congestive Heart Failure Hospitalizations and Cannabis Use Disorder (2010-2014): National Trends and Outcomes
}

\author{
Temitope Ajibawo ${ }^{1}$, Uvie Ajibawo-Aganbi ${ }^{2}$, Farla Jean-Louis ${ }^{1}$, Rikinkumar S. Patel ${ }^{3}$ \\ 1. Internal Medicine, Brookdale University Hospital Medical Center, New York City, USA 2. Health Sciences, Essen \\ Health Care, New York City, USA 3. Psychiatry, Griffin Memorial Hospital, Norman, USA
}

Corresponding author: Temitope Ajibawo, topajibawo@gmail.com

\begin{abstract}
Background and objectives: Prior studies have suggested that cannabis use is an independent risk factor for heart failure. With increasing recreational use of cannabis and decriminalization policies, cannabis use is expected to add to the burden of heart failure, but there is still limited data. Therefore, we utilized the Nationwide Inpatient Sample (NIS) database (2010-2014) to study the national trends and outcomes among cannabis users admitted for congestive heart failure (CHF).
\end{abstract}

Methods: We queried the NIS database and identified CHF as the primary diagnosis with a co-diagnosis of cannabis use disorder (CUD). Trends were analyzed with the linear-by-linear association.

Results: Total CHF admissions ( $N=4,596,024)$ with comorbid CUD $(\mathrm{N}=23,358(0.5 \%))$ were identified. An increasing prevalence trend from $0.4 \%$ to $0.7 \%(\mathrm{P}=0.001)$ was seen. CUD patients had a mean age of 49.78 years, $79 \%$ were males, $55.4 \%$ were African Americans, and $73.6 \%$ earn $\leqslant 50$ th percentile median household income of the patient's ZIP code. Inpatient deaths $(1.1 \%$ vs. $3.1 \%)$ were lower $(\mathrm{P}<0.001)$, and mean length of stay (LOS) was shorter among cannabis users compared to non-users $(\mathrm{P}=0.001)$. The mean LOS and total hospitalization costs demonstrated an increasing trend $\left(P_{\text {trend }}=0.001\right.$ and $\left.P_{\text {trend }}<0.001\right)$ respectively. Alcohol abuse and depression were more prevalent among CUD compared to non-CUD patients.

Conclusion: CUD was associated with reduced inpatient deaths, but the prevalence of CUD and hospital charges is on the rise in the CHF inpatient population in addition to shorter mean LOS. Notwithstanding, these above findings prompt further research into its underlying mechanisms along with a probable causal relationship between cannabis and heart failure.

Categories: Cardiology, Internal Medicine, Psychiatry

Keywords: congestive heart failure, cannabis use disorder, marijuana, trends, mortality, length of stay

Received 06/12/2020

Review began 06/24/2020 Review ended 06/24/2020 Published 07/02/2020

๑) Copyright 2020 Ajibawo et al. This is an open access article distributed under the terms of the Creative Commons Attribution License CC-BY 4.0., which permits unrestricted use, distribution, and reproduction in any medium, provided the original author and source are credited.

\section{Introduction}

The past decade has witnessed unprecedented legalization and decriminalization of cannabis use across many states in the United States [1]. However, cannabis still maintains its status as a strictly prohibited drug at the federal level [1]. Marijuana is currently the most commonly used recreational drug in the United States, with >22 million users per month [2]. As of December 2018, marijuana was legal for medicinal use in thirty-three states and the District of Columbia (DC), while ten states and DC have enacted policies enabling recreational marijuana use [3].

Heart failure constitutes a significant public health issue, and its estimated prevalence is $>5.7$ million in the United States (US) [4]. Heart failure also constitutes a huge strain on the health care system, responsible for health care costs greater than $\$ 39$ billion annually in the US [4]. The lifetime risk of developing heart failure is estimated to be $20 \%$ [4]. Thus, the consensus from a few published case reports and studies is that cannabis use may be associated with the development of left ventricular dysfunction and heart failure [5-8]

However, there is a dearth of systematic studies evaluating outcomes and trends of cannabis use disorder (CUD) in acute heart failure.

Based on limited data on comorbid CUD in heart failure patients, our study used Nationwide Inpatient Sample (NIS) data to determine the trends of demographic factors, in-hospital outcomes, and comorbidities for congestive heart failure (CHF) hospitalizations and cannabis use. Next, we compared in-hospital outcomes among CUD vs. non-CUD patients admitted for CHF

\section{Materials And Methods}

\section{Data source}


We used the NIS data in our study and diagnostic information was obtained using the International Classification of Diseases, Ninth Revision, Clinical Modification (ICD-9-CM) codes, and clinical classification (CCS) codes [9].

\section{Inclusion criteria}

We identified 4,596,024 patients with a primary discharge diagnosis of CHF using ICD-9-CM codes of 398.91, $402.01,402.11,402.91,404.01,404.03,404.11,404.13,404.91,404.93,428.0-428.9$ and 23,358 patients with co-morbid CUD using ICD-9-CM codes 304.30-304.32, and 305.2.

\section{Variables of interest}

To study the demographic trends in patients admitted for CHF with CUD from 2010-2014, we included demographic factors such as age, race, gender, household income, and primary payer status [10]. We compared the baseline demographics and in-hospital outcomes-length of stay (LOS), in-hospital mortality, and total hospital costs) between CUD and non-CUD patients admitted for CHF.

Comorbidities were considered coexisting clinical conditions to CHF. For assessment of comorbidities, the Agency for Healthcare Research and Quality (AHRQ) comorbidity software was used to create binary variables [11], then ICD-9 CM diagnosis codes were used to identify comorbidities. The ICD-9 CM codes used to determine the comorbid conditions are available in the appendices. We also applied discharge weights (DISCWT) to obtain a nationwide representative sample population [10].

\section{Statistical analyses}

Statistical analysis was done by SPSS version 25 (IBM, Armonk, NY, US). We used the independent sample ttest and analysis of variance (ANOVA) for measuring continuous data. Pearson's chi-square test was used for categorical data. Trends were analyzed with the linear-by-linear association tests. A p-value $\leqslant 0.05$ was used to define the statistical significance of the tests. The NIS database did not contain any personally identifiable information. Therefore, an institutional review board (IRB) approval was not needed for this study.

\section{Results}

\section{Demographics, inpatient outcomes and trends}

The total number of admissions identified with a primary diagnosis of CHF over the five years was $\mathrm{N}=$ $4,596,024$, and $0.5 \%(\mathrm{~N}=23,358)$ of these patients had a co-diagnosis of CUD as shown in Table 1 below.

\begin{tabular}{|c|c|c|c|c|c|}
\hline \multirow{3}{*}{ Variable } & \multicolumn{2}{|c|}{$\mathrm{CHF}, \mathrm{N}=4,596,024$} & & & \\
\hline & Non-CUD & & \multicolumn{2}{|l|}{ CUD } & \multirow{2}{*}{ P-Value } \\
\hline & $\mathrm{N}$ & $\%$ & $\mathbf{N}$ & $\%$ & \\
\hline Total admissions & $4,572,666$ & 99.5 & 23,358 & 0.5 & \\
\hline Mean age at admission (SD), in years & \multicolumn{2}{|l|}{72.77 (14.43) } & \multicolumn{2}{|l|}{$49.78(11.24)$} & $<0.001$ \\
\hline \multicolumn{6}{|l|}{ Sex } \\
\hline Males & $2,296,127$ & 50.2 & 18,448 & 79.0 & \multirow{3}{*}{$<0.001$} \\
\hline Females & $2,276,092$ & 49.8 & 4910 & 21.0 & \\
\hline \multicolumn{5}{|l|}{ Race } & \\
\hline White & $2,920,078$ & 68.4 & 7111 & 31.9 & \multirow{4}{*}{$<0.001$} \\
\hline African Americans & 831,467 & 19.5 & 12,362 & 55.4 & \\
\hline Hispanic & 32,090 & 7.5 & 1803 & 8.1 & \\
\hline Other & 197,758 & 4.6 & 1034 & 4.6 & \\
\hline \multicolumn{6}{|l|}{ Median household income, in percentile } \\
\hline $0-25$ th & $1,481,175$ & 33.1 & 11,666 & 51.8 & \multirow{4}{*}{$<0.001$} \\
\hline 26th-50th & $1,184,624$ & 26.4 & 5157 & 22.9 & \\
\hline 51st-75th & $1,020,324$ & 22.8 & 3906 & 17.4 & \\
\hline 76th-100th & 793,574 & 17.7 & 1781 & 7.9 & \\
\hline
\end{tabular}




\section{Cureus}

\begin{tabular}{|c|c|c|c|c|c|}
\hline \multicolumn{6}{|l|}{ Primary payer } \\
\hline Medicare & 344,360 & 75.5 & 6505 & 27.9 & \multirow{4}{*}{$<0.001$} \\
\hline Medicaid & 369,350 & 8.1 & 8950 & 38.5 & \\
\hline Private & 523,995 & 11.5 & 2488 & 10.7 & \\
\hline Self-pay or uninsured & 147,146 & 3.2 & 4164 & 17.9 & \\
\hline Others & 79,127 & 1.7 & 1169 & 5.0 & \\
\hline \multicolumn{6}{|l|}{ Comorbidities } \\
\hline Alcohol abuse & 126,464 & 2.8 & 6075 & 26.0 & $<0.001$ \\
\hline Depression & $4,555,384$ & 10.0 & 2500 & 10.7 & $<0.001$ \\
\hline Diabetes, without complications & $1,574,996$ & 34.4 & 5704 & 24.4 & $<0.001$ \\
\hline Diabetes, with complications & 478,489 & 10.5 & 3700 & 7.7 & $<0.001$ \\
\hline Hypertension & $3,436,096$ & 75.1 & 17,276 & 74.0 & $<0.001$ \\
\hline Metastatic cancer & 45,995 & 1.0 & 89 & 0.4 & $<0.001$ \\
\hline Renal failure & 188,1371 & 41.1 & 7153 & 30.6 & $<0.001$ \\
\hline \multicolumn{6}{|l|}{ Severity of illness } \\
\hline Nil & 221 & $<0.1$ & 0 & 0.0 & \multirow{4}{*}{0.001} \\
\hline Minor & 324,608 & 7.1 & 2263 & 9.7 & \\
\hline Moderate & $1,680,851$ & 36.8 & 9154 & 39.2 & \\
\hline Major & $2,566,986$ & 56.1 & 11,941 & 51.1 & \\
\hline \multicolumn{6}{|l|}{ Other hospital outcomes } \\
\hline Mean length of stay (SD), in days & $5.19(5.82)$ & & $4.62(4.98)$ & & 0.001 \\
\hline Mean total charges in (USD) & 40,730 & & 41,642 & & 0.08 \\
\hline In-hospital mortality & $140,8 / 8$ & 3.1 & 249 & 1.1 & $<0.001$ \\
\hline
\end{tabular}

TABLE 1: Baseline characteristics of CHF hospitalizations by comorbid CUD.

$P \leq 0.05$ indicates statistical significance.

CHF: congestive heart failure; CUD: cannabis use disorder; USD: United States Dollars; N: number; SD: standard deviation.

The proportion of total CUD admissions had an increasing trend from $0.4 \%(\mathrm{~N}=3588)$ in 2010 to $0.7 \%(\mathrm{~N}=$ 6365) in 2014, which represents a 77.4\% ( $\left.\mathrm{P}_{\text {trend }}<0.001\right)$ increase over the five years as shown in Table 2 below. 


\begin{tabular}{|c|c|c|c|c|c|c|c|c|}
\hline Variables & 2010 & 2011 & 2012 & 2013 & 2014 & $\begin{array}{l}\text { Overall } \\
\text { Total }\end{array}$ & $P_{\text {trend }}$ & $\begin{array}{l}\text { Trend } \\
\text { Direction }\end{array}$ \\
\hline No Of CUD admissions & 3588 & 3970 & 4305 & 5130 & 6365 & 23,358 & & \\
\hline $\begin{array}{l}\text { CUD admissions prevalence } \\
\text { (\%) }\end{array}$ & 0.4 & 0.4 & 0.5 & 0.6 & 0.7 & 0.5 & $<0.001$ & Increasing \\
\hline \multicolumn{9}{|l|}{ Age at admission } \\
\hline Mean age (SD) (in years) & $\begin{array}{l}48.08 \\
(11.41)\end{array}$ & $\begin{array}{l}48.93 \\
(11.22)\end{array}$ & $\begin{array}{l}50.11 \\
(11.22)\end{array}$ & $\begin{array}{l}50.25 \\
(10.81)\end{array}$ & $\begin{array}{l}50.65 \\
(11.38)\end{array}$ & $\begin{array}{l}49.78 \\
(11.24)\end{array}$ & $<0.001$ & Increasing \\
\hline \multicolumn{9}{|l|}{ Gender (\%) } \\
\hline Males & 81.7 & 78.9 & 81.2 & 78.9 & 76.0 & 79 & 0.001 & Decreasing \\
\hline Females & 18.3 & 21.1 & 18.8 & 21.1 & 24.0 & 21.0 & 0.001 & Increasing \\
\hline \multicolumn{9}{|l|}{ Race (\%) } \\
\hline Whites & 25.7 & 33.7 & 27.8 & 33.9 & 35.3 & 31.9 & 0.466 & Increasing \\
\hline African Americans & 64.1 & 52.8 & 57.8 & 53.6 & 52.1 & 55.4 & 0.466 & Decreasing \\
\hline Hispanics & 7.4 & 9.7 & 8.3 & 7.8 & 7.6 & 8.1 & 0.466 & Increasing \\
\hline Others & 2.8 & 3.8 & 6.2 & 4.7 & 5.0 & 4.6 & 0.466 & Increasing \\
\hline \multicolumn{9}{|l|}{ Income level (\%) } \\
\hline 0-25th percentile & 54.3 & 49.7 & 53.2 & 48.5 & 53.5 & 51.8 & 0.851 & Variable \\
\hline 26th-50th percentile & 22.7 & 21.1 & 21.7 & 25.4 & 23.0 & 22.9 & 0.851 & Variable \\
\hline 51st-75th percentile & 16.8 & 19.6 & 17.8 & 17.4 & 15.9 & 17.4 & 0.851 & Variable \\
\hline 76th-100th percentile & 6.2 & 9.5 & 7.3 & 8.8 & 7.6 & 7.9 & 0.851 & Increasing \\
\hline \multicolumn{9}{|l|}{ Insurance (\%) } \\
\hline Medicare & 26.3 & 27.2 & 28.3 & 27.9 & 29.1 & 27.9 & $<0.001$ & Increasing \\
\hline Medicaid & 34.5 & 35.6 & 36.8 & 36.5 & 45.1 & 38.4 & $<0.001$ & Increasing \\
\hline Private & 13.2 & 11.5 & 10.0 & 10.4 & 9.4 & 10.7 & $<0.001$ & Decreasing \\
\hline Self-pay & 20.2 & 19.2 & 18.6 & 19.5 & 14.0 & 17.9 & $<0.001$ & Decreasing \\
\hline Other & 5.7 & 6.4 & 6.3 & 5.7 & 2.4 & 5.0 & $<0.001$ & Variable \\
\hline \multicolumn{9}{|l|}{ Severity of Illness (\%) } \\
\hline Minor & 8.9 & 8.8 & 10.9 & 11.4 & 8.5 & 9.7 & 0.946 & Variable \\
\hline Moderate & 39.4 & 37.5 & 41.8 & 39.3 & 38.3 & 39.2 & 0.946 & Variable \\
\hline Major & 51.7 & 53.6 & 47.3 & 49.3 & 53.3 & 51.1 & 0.946 & Variable \\
\hline \multicolumn{9}{|l|}{ Other hospital outcomes } \\
\hline In-hospital mortality (\%) & 0.7 & 0.8 & 1.5 & 1.2 & 1.0 & 1.1 & 0.137 & Increasing \\
\hline Mean total charges in USD & 34,776 & 44,100 & 41,729 & 42,451 & 43,292 & 41,642 & $<0.001$ & Increasing \\
\hline $\begin{array}{l}\text { Mean length of stay (SD) (in } \\
\text { days) }\end{array}$ & $4.21(3.58)$ & $4.61(4.39)$ & $4.72(5.30)$ & $4.76(5.95)$ & $4.66(4.91)$ & 4.62 (4.98) & 0.001 & Increasing \\
\hline
\end{tabular}

TABLE 2: Trends of demographics and hospital outcomes of CUD in CHF inpatients.

$P \leq 0.05$ indicates statistical significance.

CHF: congestive heart failure; CUD: cannabis use disorder; USD: United States Dollars; SD: standard deviation. 
The mean age of CUD patients increased significantly from $48.08 \pm 11.41$ years in 2010 to $49.78 \pm 11.24$ years $\left(\mathrm{P}_{\text {trend }}<0.001\right)$. Males $(79 \%)$ constituted most of the cannabis users, but there was a significant declining trend of CUD prevalence from $81.7 \%$ in 2010 to $76.0 \%$ in $2014\left(\mathrm{P}_{\text {trend }}=0.001\right)$. Conversely, CUD prevalence among females increased from $18.3 \%$ to $21.0 \%$ in the five years $\left(P_{\text {trend }}=0.001\right)$. More than half of cannabis users were African Americans, followed by Caucasians (31.9\%), Hispanics (8.1\%), and others (4.6\%). CUD prevalence among Whites and Hispanics followed an increasing trend but followed a decreasing trend among African Americans. All race groups showed a non-statistically significant trend $\left(\mathrm{P}_{\text {trend }}=0.466\right)$.

Regarding median household income in percentiles, CUD prevalence among patients below the 25th percentile, 26th to 50th percentile, and 51st to 75 th percentile showed a variable trend, while CUD prevalence in the highest percentile demonstrated an increasing trend from 2010 to $2014\left(\mathrm{P}_{\text {trend }}=0.851\right)$. Patients below the 25th percentile represented about half of the CUD admissions.

In terms of insurance status, Medicaid was the primary insurance for $38.4 \%$ of the total CUD population, while Medicare was the primary payer for $27.9 \%$. Both Medicaid and Medicare payments had an increasing trend $\left(\mathrm{P}_{\text {trend }}<0.001\right)$. Private insurance and self-pay mode of payment followed statistically significant down-trend payments from $13.2 \%$ to $9.4 \%$ and $20.2 \%$ to $14 \%$ over the five years $\left(\mathrm{P}_{\text {trend }}<0.001\right)$ respectively.

Cannabis users with major morbidity made up 51.1\% of the total CUD population, and there was a nonstatistically significant variable trend from January 2010 to December $2014\left(\mathrm{P}_{\text {trend }}=0.946\right)$. In-hospital mortality (1.1\% vs. 3.1\%), was lower, and mean LOS in days were shorter in CUD patients compared to the non-CUD cohort $(\mathrm{P}<0.001)$ and $(\mathrm{P}=0.001)$ respectively. There was a non-statistical difference in total hospital charges between CUD and non-CUD patients $(\mathrm{P}=0.08)$.

In-hospital mortality among CUD patients followed a non-statistically significant trend from $0.7 \%$ to $1.1 \%$ from 2010 to 2014 ( $\mathrm{P}_{\text {trend }}<0.137$ ), but there were a significant trend increase from 2010 to 2014 for both LOS in days $\left(\mathrm{P}_{\text {trend }}=0.001\right)$ and total hospital charges $\left(\mathrm{P}_{\text {trend }}<0.001\right)$.

\section{Comorbidities and trends}

Comorbidities of diabetes, hypertension, renal failure, and metastatic cancer were less prevalent among cannabis users as shown in Figure 1 below.

\section{FREQUENCY OF COMORBIDITIES IN CUD VS NON-CUD}

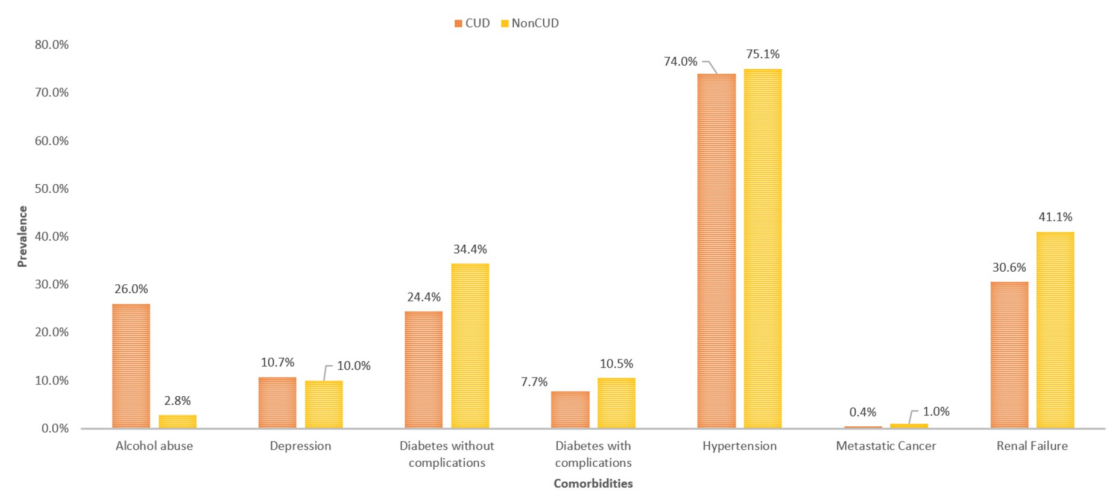

FIGURE 1: Frequency of comorbid conditions in CUD vs. non-CUD CHF inpatients.

CHF: congestive heart failure; CUD: cannabis use disorder.

At the same time, alcohol abuse and depression were more prevalent among CUD patients. Alcohol abuse showed a significant decreasing trend from 2010 to $2014\left(\mathrm{P}_{\text {trend }}<0.001\right)$ as shown in Table 3 below 


\begin{tabular}{|l|l|l|l|l|l|l|l|l|}
\hline Comorbidities & 2010 & 2011 & 2012 & 2013 & 2014 & Total & $\mathbf{P}_{\text {trend }}$ & Trend Direction \\
\hline Alcohol abuse & $27.1 \%$ & $26.9 \%$ & $27.1 \%$ & $26.1 \%$ & $24.0 \%$ & $26.0 \%$ & $<0.001$ & Decreasing \\
Depression & $10.4 \%$ & $11.4 \%$ & $10.1 \%$ & $10.3 \%$ & $11.2 \%$ & $10.7 \%$ & 0.621 & Variable \\
Diabetes without complications & $22.1 \%$ & $22.4 \%$ & $26.5 \%$ & $24.9 \%$ & $25.2 \%$ & $24.4 \%$ & $<0.001$ & Increasing \\
Diabetes with complications & $6.2 \%$ & $8.1 \%$ & $6.6 \%$ & $8.0 \%$ & $8.6 \%$ & $7.7 \%$ & $<0.001$ & Increasing \\
Hypertension & $73.9 \%$ & $73.4 \%$ & $74.7 \%$ & $73.2 \%$ & $74.5 \%$ & $74.0 \%$ & 0.590 & Variable \\
Metastatic Cancer & $0.3 \%$ & $0.4 \%$ & $0.1 \%$ & $0.8 \%$ & $0.3 \%$ & $0.4 \%$ & 0.126 & Variable \\
Renal failure & $30.6 \%$ & $30.6 \%$ & $29.8 \%$ & $30.4 \%$ & $31.3 \%$ & $30.6 \%$ & 0.412 & Stable \\
\hline
\end{tabular}

TABLE 3: Trends of comorbidities associated with CUD in CHF patients.

$p \leq 0.05$ indicates statistical significance.

CHF: congestive heart failure; CUD: cannabis use disorder.

Conversely, diabetes, with and without complications significantly increased in a linear trend from 2010 to $2014\left(\mathrm{P}_{\text {trend }}<0.001\right)$.

Comorbidities of hypertension $\left(\mathrm{P}_{\text {trend }}=0.590\right)$, depression $\left(\mathrm{P}_{\text {trend }}=0.621\right)$, and metastatic cancer $\left(\mathrm{P}_{\text {trend }}=\right.$ $0.126)$ showed a non-significant variable trend. Renal failure was the only comorbidity that showed a stable linear trend.

\section{Discussion}

This study considered demographic factors (age, race, gender, insurance type, household income), the severity of illness, in-hospital mortality, total hospital charges, and LOS in both cannabis users and nonusers. Trends of coexisting comorbidities among CHF hospitalizations with CUD was also explored. We reported an overall prevalence of CUD among CHF inpatients as $0.5 \%$ and a significant trend of $77.4 \%$. These findings are similar to a recent study by Charilaou et al. that reported an increase in cannabis abuse prevalence in patient populations from $0.5 \%$ to $1.3 \%$ from 2002 to 2011 [12]. Our observation may be partially explained by the legalization of medical and recreational cannabis in the many U.S. states [13,14], which consecutively led to an increase in the prevalence of cannabis users in the general population, and by extension increased the odds of observing them in admitted patients, including CHF hospitalizations [12].

In another study of cannabis use, Kalla et al. showed that cannabis use was an independent risk predictor of heart failure [8]. Evidence of this association between cannabis use and heart failure is backed by prior human and animal studies [15-18]. Three earlier studies showed that endocannabinoids acting on CB-1 receptors caused decreased myocardial contractility [15-17]. Su et al. also showed that the negative inotropy activity of CB2 agonists, independent of CB1 and CB2 receptors, causes decreased myocardial contractility [18].

Our study showed that cannabis users were predominantly males (79\%) with a mean age of 49.8 years. These findings are consistent with findings by Wu and colleagues in a study of the effects of marijuana use on heart failure, which reported a mean age of 50.4 years and predominance of males $(78.3 \%)$ among marijuana users compared to non-users [19].

Two notable findings of this study are the lower mortality rate (1.1\% vs. 3.1\%) and reduced LOS (4.62 vs. 5.12 days) among cannabis users compared to non-cannabis users. These results are similar to findings of a previous study that marijuana use was associated with reduced inpatient mortality (odds ratio (OR): 0.197 $(0.046-0.083) \mathrm{p}=0.0142)$ and reduced LOS $(4.2 \pm 0.1 \mathrm{vs.} 4.8 \pm 0.2, \mathrm{p}=0.0038)$ in patients admitted for heart failure [19]. We hypothesized that the lower mortality among CUD patients admitted for heart failure is due to the relatively younger age of this cohort, which makes it possible that the baseline risk of dying in these patients was less than that of non-cannabis users. Another possible explanation for the lower mortality is reduced severity of illiness among cannabis users.

A possible explanation for the reduced mean LOS among cannabis users could be a reduced severity of CHF illness. Notwithstanding these findings require further investigation in the future. This study demonstrated a statistically significant increase in LOS among cannabis users from 2010 to 2014, which we believe caused an increase in hospital charges from $(\$ 34,776$ to $\$ 43,292)$. Unlike our study which did not show any significant differences in hospital costs between CUD and non-CUD patients, a prior study by Wu et al. [19] 
demonstrated a significantly lower hospital cost among cannabis users vs. non-users. Although the reason for the above finding is largely speculative, this contrasting finding from previous observation is a significant addition to the body of literature.

Our study revealed essential differences in demographic factors between CUD and non-CUD patients admitted for CHF. Patients hospitalized for CHF with CUD were mostly younger men of African American origin and earned less than the 50th percentile household income. Like our study, it was reported by Nishimura et al. that patients hospitalized for heart failure who had a history of substance abuse were mostly males, and likely to be African American and younger [20].

Alcohol abuse (74\% vs. 26\%) had a higher prevalence among cannabis users compared to non-CUD. Previous studies of cannabis use in the inpatient population support this finding. Charilaou et al. explored comorbidities associated with cannabis use disorder in inpatients between 2002 to 2011 using the AHRQ comorbidity indicators and reported alcohol abuse as one of the primary comorbid conditions associated with cannabis use [12]. In the same study, approximately $33 \%$ of inpatient cannabis users were reported to have a history of alcohol abuse [12]. Similarly, another study that reported alcohol study surveys of marijuana and other illicit drugs revealed that most marijuana users were either binge drinkers or users of other substances [21]. Furthermore, Smit and Crespo studied the nutritional status of adult cannabis users and found out that cannabis users consume higher proportions of alcohol compared to non-users [22]. It is worth mentioning that alcohol abuse is associated with alcoholic cardiomyopathy [23], which is characterized by increased left ventricular mass, left ventricular dilation along with reduced and/or normal ventricular wall thickness [24]

Alcohol abuse as a comorbidity demonstrated a statistically significant decreasing trend from 2010 to 2014 . A possible explanation for this phenomenon is the "substitution effect" of alcohol with cannabis use and other illicit drugs by cannabis users $[25,26]$.

Our results showed a higher prevalence of depression among cannabis users vs. non-users (10.7\% vs. $10 \%)$. Long term use of cannabis has been previously linked with depression [27]. In a prior study of heart failure patients with depression, $15 \%$ of these patients were found to have substance abuse problems [28].

This present study has a few limitations that should be considered when interpreting the results. Based on the administrative nature of the NIS database, there is a possibility of coding inaccuracies and classification errors. Secondly, due to the contentious legal and societal status of cannabis use, reporting of cannabis abuse is prone to underreporting bias. Based on the nature of the database, there was unavailability of patient-level information; therefore, adjustment for confounders could not be performed during analysis. Our study, being an observational study, could not assess a temporal relationship between cannabis use and CHF. The level of exposure to cannabis use could not be assessed because of the unavailability of the information in the database, so we were unable to comment on the quantity of cannabis.

Despite these limitations, the NIS database provides an invaluable population-based resource for evaluating national trends. Another strength of this study is obtained from the large sample size of the NIS data, which has enough power to determine differences between CUD and non-CUD CHF populations. Findings from our study also serve as hypotheses and a valuable reference for further research.

\section{Conclusions}

Among CUD patients hospitalized for CHF, the trend for the total number of admissions, mean LOS and mean total charges increased significantly over the five-year period of study. In addition, CUD patients had less all-cause in-hospital deaths and shorter hospital stays compared to non-users. Moreover, cannabis users followed a specific demographic profile as they were mostly males, African Americans, and lower-income earners. Further in-depth research is warranted to explore a causal relationship between cannabis use and the development of heart failure

\section{Appendices}




\section{Cureus}

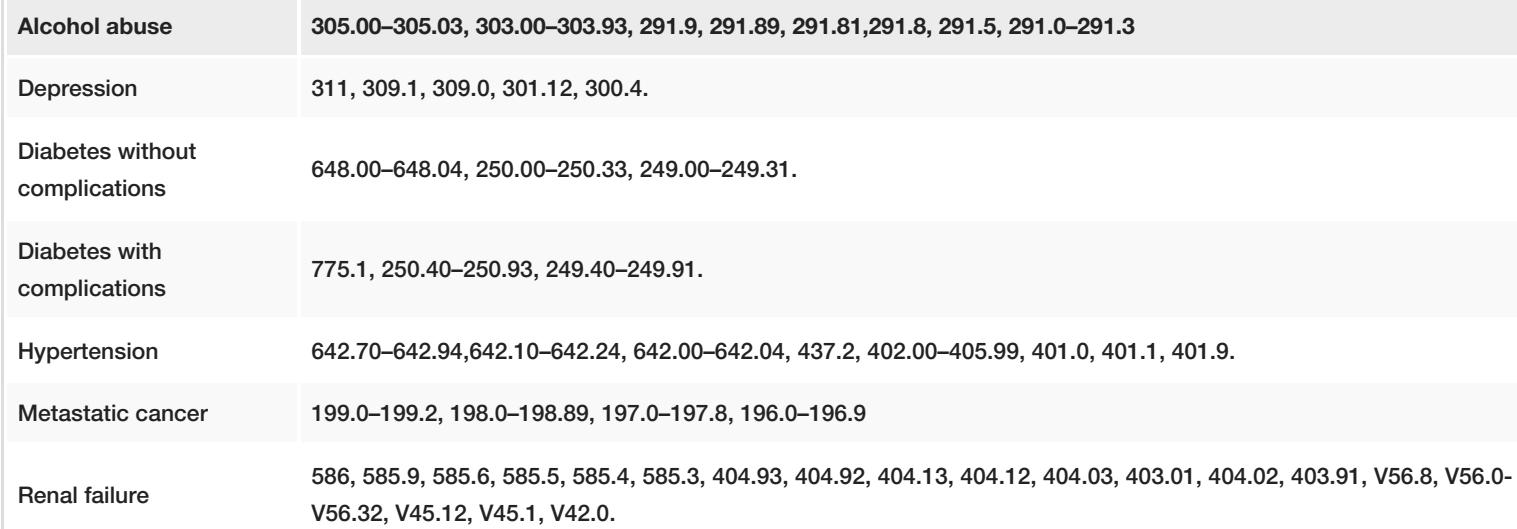

TABLE 4: ICD-9 CM codes for co-morbid conditions

\section{Additional Information \\ Disclosures}

Human subjects: Consent was obtained by all participants in this study. Animal subjects: All authors have confirmed that this study did not involve animal subjects or tissue. Conflicts of interest: In compliance with the ICMJE uniform disclosure form, all authors declare the following: Payment/services info: All authors have declared that no financial support was received from any organization for the submitted work. Financial relationships: All authors have declared that they have no financial relationships at present or within the previous three years with any organizations that might have an interest in the submitted work. Other relationships: All authors have declared that there are no other relationships or activities that could appear to have influenced the submitted work.

\section{Acknowledgements}

Some of the results in this manuscript were presented at the American College of Cardiology Scientific Meeting in March 2020

\section{References}

1. Smart R, Pacula RL: Early evidence of the impact of cannabis legalization on cannabis use, cannabis use disorder, and the use of other substances: findings from state policy evaluations. Am J Drug Alcohol Abuse. 2019, 45:644-663. 10.1080/00952990.2019.1669626

2. Key substance and mental health indicators in the United States: results from the 2015 national survey on drug use and health. (2015). Accessed: May 12, 2020: https://www.samhsa.gov/data/sites/default/files/NSDUH-FFR1-2015/NSDUH-FFR1-2015/NSDUH-FFR12015.htm.

3. Marijuana deep dive: National Conference of State Legislatures . (2018). Accessed: May 12, 2020: http://www.ncsl.org/bookstore/state-legislatures-magazine/marijuana-deep-dive.aspx.

4. Bui AL, Horwich TB, Fonarow GC: Epidemiology and risk profile of heart failure . Nat Rev Cardiol. 2011, 8:30-41. 10.1038/nrcardio.2010.165

5. Kaushik M, Alla VM, Madan R, Arouni AJ, Mohiuddin SM: Recurrent stress cardiomyopathy with variable regional involvement: insights into etiopathogenetic mechanisms. Circulation. 2011, 124:e556-e557. 10.1161/circulationaha.111.059329

6. Nogi M, Fergusson D, Chiaco JM: Mid-ventricular variant takotsubo cardiomyopathy associated with cannabinoid hyperemesis syndrome: acase report. Hawaii J Med Public Health. 2014, 73:115-118.

7. Singh A, Agrawal S, Fegley M, Manda Y, Nanda S, Shirani J: Marijuana (cannabis) use is an independent predictor of stress cardiomyopathy in younger men. Circulation. 2016, 134:

8. Kalla A, Krishnamoorthy PM, Gopalakrishnan A, Figueredo VM: Cannabis use predicts risks of heart failure and cerebrovascular accidents: results from the National Inpatient Sample. J Cardiovasc Med. 2018, 19:480484. 10.2459/jcm.0000000000000681

9. Overview of the National (Nationwide) Inpatient Sample (NIS) . (2019). Accessed: October 20, 2019: https://www.hcup-us.ahrq.gov/nisoverview.jsp.

10. NIS description of data elements. (2019). Accessed: October 20, 2019: https://www.hcupus.ahrq.gov/db/nation/nis/nisdde.jsp.

11. Elixhauser comorbidity software, version 3.7 . (2017). Accessed: October 20, 2019: https://www.hcupus.ahrq.gov/toolssoftware/comorbidity/comorbidity.jsp.

12. Charilaou P, Agnihotri K, Garcia P, Badheka A, Frenia D, Yegneswaran B: Trends of cannabis use disorder in the inpatient: 2002 to 2011. Am J Med. 2017, 130:678-687.e7. 10.1016/j.amjmed.2016.12.035

13. Hoffmann DE, Weber E: Medical marijuana and the law. N Engl J Med. 2010, 362:1453-1457. 
10.1056/NEJMp1000695

14. Cerdá M, Wall M, Keyes KM, Galea S, Hasin D: Medical marijuana laws in 50 states: Investigating the relationship between state legalization of medical marijuana and marijuana use, abuse and dependence. Drug Alcohol Depend. 2012, 120:22-27. 10.1016/j.drugalcdep.2011.06.011

15. Bátkai S, Pacher P, Osei-Hyiaman D: Endocannabinoids acting at cannabinoid-1 receptors regulate cardiovascular function in hypertension. Circulation. 2004, 110:1996-2002. 10.1161/01.Cir.0000143230.23252.D2

16. Bonz A, Laser M, Küllmer S: Cannabinoids acting on CB1 receptors decrease contractile performance in human atrial muscle. J Cardiovasc Pharm. 2003, 41:657-664. 10.1097/00005344-200304000-00020

17. Pacher P, Bátkai S, Kunos G: Haemodynamic profile and responsiveness to anandamide of TRPV1 receptor knock-out mice. J Physiol. 2004, 558:647-657. 10.1113/jphysiol.2004.064824

18. Su Z, Preusser L, Diaz G: Negative inotropic effect of a CB2 agonist A-955840 in isolated rabbit ventricular myocytes is independent of CB1 and CB2 receptors. Curr Drug Saf. 2011, 6:277-284. 10.2174/157488611798918728

19. Wu L, Narasimhan B, Ho KS, Li P: Marijuana use is associated with better hospital outcome in patients with acute heart failure: a propensity match analysis from national inpatient database. J Card Fail. 2019, 25:S158. 10.1016/j.cardfail.2019.07.452

20. Nishimura M, Bhatia H, Ma J: The impact of substance abuse on heart failure hospitalizations . Am J Med. 2020, 133:207-213.e1. 10.1016/j.amjmed.2019.07.017

21. Mohler-Kuo M, Lee JE, Wechsler H: Trends in marijuana and other illicit drug use among college students: results from 4 Harvard School of Public Health College Alcohol Study surveys: 1993-2001. J Am Coll Health. 2003, 52:17-24. 10.1080/07448480309595719

22. Smit E, Crespo CJ: Dietary intake and nutritional status of U.S. adult marijuana users: results from the Third National Health and Nutrition Examination Survey. Public Health Nutr. 2001, 4:781-786. $10.1079 / \mathrm{phn} 2000114$

23. Lazarević AM, Nakatani S, Nesković AN, et al.: Early changes in left ventricular function in chronic asymptomatic alcoholics: relation to the duration of heavy drinking. J Am Coll Cardiol. 2000, 35:1599-1606. 10.1016/s0735-1097(00)00565-9

24. Piano MR: Alcoholic cardiomyopathy: incidence, clinical characteristics, and pathophysiology. Chest. 2002, 121:1638-1650. 10.1378/chest.121.5.1638

25. Lucas P, Reiman A, Earleywine M, et al.: Cannabis as a substitute for alcohol and other drugs: a dispensarybased survey of substitution effect in Canadian medical cannabis patients. Addict Res Theory. 2013, 21:435442. 10.3109/16066359.2012.733465

26. Lucas P, Baron EP, Jikomes N: Medical cannabis patterns of use and substitution for opioids \& other pharmaceutical drugs, alcohol, tobacco, and illicit substances; results from a cross-sectional survey of authorized patients. Harm Reduct J. 2019, 16:9. 10.1186/s12954-019-0278-6

27. Reilly D, Didcott P, Swift W, Hall W: Long-term cannabis use: characteristics of users in an Australian rural area. Addiction. 1998, 93:837-846. 10.1046/j.1360-0443.1998.9368375.x

28. Patel RS, Shrestha S, Saeed H, et al.: Comorbidities and consequences in hospitalized heart failure patients with depression. Cureus. 2018, 10:e3193. 10.7759/cureus.3193 